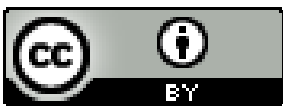

\title{
OPÇÃO DECOLONIAL E ANTIRRACISMO NA EDUCAÇÃO EM TEMPOS NEOFASCISTAS
}

\author{
Luiz Fernandes de Oliveira ${ }^{1}$
}

\begin{abstract}
Resumo: Este artigo é uma reflexão epistêmica e política a partir da nova realidade brasileira neoconservadora instalada a partir de 2016 e aprofundada com a eleição de um governo de ultradireita a partir de 2018. Nesta nova conjuntura, apresentamos os possíveis riscos políticos do fim de uma legislação antirracista na educação brasileira (a Lei 10.639/03) e quais os possíveis caminhos de uma insurgência política e epistêmica para reafirmar que a produção de um conhecimento antirracista em educação depende fundamentalmente do engajamento político e epistêmico em lutas concretas contra o racismo estrutural brasileiro. Enfim, a perspectiva que trabalharemos neste texto é aquela de que o horizonte da utopia igualitária em educação está sempre presente, pois aprendemos com a história que aquilo que foi impossível e inimaginável um dia, se concretizou a partir da ação política insurgente de sujeitos coletivos que assumiram a tarefa de transformar sua realidade.
\end{abstract}

Palavras Chaves: antirracismo, opção decolonial, Lei 10.639, militância, educação

\section{DECOLONIAL AND ANTI-RA CISM OPTION IN EDUCATION IN NEO-FASCIST TIMES}

Abstract: This article is an epistemic and political reflection based on the new neoconservative Brazilian reality installed in 2016 and deepened with the election of an ultra-right government in 2018. In this new conjuncture, we present the possible political risks of the end of an anti-racist legislation in Brazilian education (Law 10.639/03) and the possible paths of a political and epistemic insurgency to reaffirm that the production of anti-racist knowledge in education depends fundamentally on political and epistemic engagement in concrete struggles against Brazilian structural racism. Ultimately, the perspective that we will aproach in this text is that the horizon of the egalitarian utopia in education is always present, since we learned from history that what was impossible and unimaginable one day, came about through the insurgent political action of collective subjects that took on the task of transforming their reality.

Keywords: anti-racism, decolonial option, Law 10.639, militancy, education

\section{OPCIÓN DECOLONIAL Y ANTIRACISMO EN LA EDUCACIÓN EN TIEMIPOS} NEOFASCISTAS

\footnotetext{
${ }^{1}$ Doutor em Educação pela PUC-Rio. Professor do Programa de Pós-Graduação em Educação, Contextos Contemporâneos e Demandas Populares - PPGEDUC e da Licenciatura em Educação do Campo da UFRRJ. Coordenador do Grupo de Pesquisa em Políticas Públicas, Movimentos Sociais e Culturas GPMC. E-mail: axeluiz@gmail.com
} 
Resumen: Este artículo es una reflexión epistémica y política basada en la nueva realidad brasileña neoconservadora instalada en 2016 y profundizada con la elección de un gobierno de ultraderecha desde 2018. En esta nueva situación, presentamos los posibles riesgos de esta política para la legislación antirracista en la educación brasileña (Ley 10.639 / 03) y cuáles son los caminos posibles de una insurgencia política y epistémica, que reafirmen que la producción de conocimiento antirracista en educación depende fundamentalmente del compromiso político y epistémico, en luchas concretas contra el racismo estructural brasileño. Finalmente, la perspectiva en que trabajamos en este artículo es que el horizonte de la utopía igualitaria en la educación está siempre presente, ya que aprendimos de la historia que lo que era imposible e inimaginable algún día, surgió a través de la acción política insurgente de sujetos colectivos que asumieron la tarea de transformar su realidad.

Palabras clave: antirracismo, opción descolonial, Ley 10.639, militancia, educación.

\section{OPTION DÉCOLONIALE ET ANTI-RACISME DANS L'ÉDUCATION EN TEMPS NÉOFASCISTES}

Résumé: Cet article fait une réflexion épistémique et politique sur la nouvelle réalité brésilienne néo-conservatrice installée en 2016 et approfondie avec l'élection d'un gouvernement d'extrême droite depuis 2018. Sur cette nouvelle conjoncture, nous présentons les risques que cette politique represente pour la législation antiraciste dans l'éducation brésilienne (loi 10.639 / 03) et les possibles voies d'une insurrection politique et épistémique, que puisse réaffirmer que la production de connaissances en anti-racisme dans l'éducation dépend fondamentalement de l'engagement politique et épistémique, dans des luttes concrètes contre le racisme structurel brésilien. Enfin, la perspective sur laquelle nous travaillons dans cet article est que l'horizon de l'utopie égalitaire dans l'éducation est toujours présent, puisque l'histoire nous a appris que ce qui était impossible et inimaginable un jour, est pourtant né de l'action politique, insurgée de sujets collectifs qui ont assumé la tâche de transformer leur réalité.

Mots-clés: antiracisme, option décoloniale, Loi 10.639, militantisme, éducation

\section{INTRODUÇÃO}

$\mathrm{Na}$ atual conjuntura está posto uma ameaça real e dolorosa para muitos militantes, docentes, estudantes e intelectuais, que é a possibilidade real do fim das Diretrizes Curriculares Nacionais para a Educação das Relações Étnico-Raciais e para o Ensino de História e Cultura Afro-Brasileira e Africana (DCNERER), que regulamentam e normatizam o artigo 26A da LDBEN. Essa ameaça surge como um monstro atrás da porta, prestes a nos engolir e sepultar definitivamente nossas energias de luta. Mas, é um monstro virtual ainda, um espectro que ronda nossas mentes e cotidiano que também nos informa o cuidado que temos que ter para saber agir e resistir.

$\mathrm{O}$ atual chefe do Governo de ultradireita, recentemente afirmou em entrevista que o racismo "é coisa rara no Brasil". Muito dos seus seguidores, com esta afirmação e outras ao longo da campanha eleitoral de 2018, estão e ficaram autorizados a repetirem 
cotidianamente uma outra afirmação que se constitui como contraponto cotidiano àqueles que lutam contra o racismo: "falar de racismo no Brasil é vitimísmo".

Esse discurso autorizado de acusação de "vitimísmo" precisa ser denominado com todas as letras, ou seja, ele significa uma militância, um engajamento político. Entretanto, esse discurso não é novidade histórica, a diferença é a intensidade legitimada oficialmente pelo chefe de governo e pela conjuntura de guerrilha implementada pelo neoconservadorismo fascista. Quando afirmamos que não é novidade, devemos aqui descrever alguns episódios que vivenciamos junto a outros docentes na educação básica no Rio de Janeiro.

Durante 4 anos (entre 1999 e 2002) atuamos como professor de sociologia, e um dos temas prioritários do currículo eram as relações raciais no Brasil. Os conteúdos que trabalhamos não se limitavam aos aspectos formais ou meramente conceituais, muito menos ficamos restritos a atuação em sala de aula. Realizamos junto aos jovens estudantes debates com militantes do movimento negro, organizamos palestras, exposições, oficinas, reflexões com vídeos de entrevistas e documentários e, por outro lado, junto os nossos pares docentes, reflexões pedagógicas acerca do antirracismo necessário às práticas pedagógicas de forma interdisciplinar.

À época, nossas ações e discursos não possuíam um lugar de legitimidade, pois o conceito de raça, por exemplo, era rechaçado por muitos colegas, por outro lado, a força do mito da democracia racial era muito forte dentro das escolas. Alguns docentes muitas vezes afirmavam que, por exemplo, a África já constava nos currículos de história quando se abordava a escravidão no Brasil colônia e o período de descolonização da África e da Ásia. Tínhamos essa reflexão por conta de nossas histórias de vida, próxima da luta antirracista e anterior ao nosso encontro na escola.

Foram anos de penúria, nadando contra a corrente, criando situações constrangedoras, na medida em que éramos julgados como aqueles que "viam racismo em tudo". Nos debates sobre evasão escolar, repetência ou sobre "alunos problemáticos", evidenciávamos a marca racial (da maioria dos casos) que perpassava os jovens envolvidos. Nossa condição não envolvia somente uma disputa ideológica, ética, pedagógica e cognitiva. Estávamos envolvidos numa proposta que vai além, ou seja, um processo de didatização para a construção de um conhecimento escolar antirracista, que não se limita ao encontro da melhor forma de trabalhar um conteúdo antirracista e com materiais adequados. 
Esse conhecimento escolar necessitava enfrentar uma dimensão que as reflexões raciais mobilizam permanentemente quando explicitadas, ou seja, as angustias, as tristezas, as dores, os medos, as humilhações e tantos outros sentimentos humanos que o racismo produz de forma negativa e que operam hierarquias e podem, inclusive, alterar a saúde dos indivíduos. Além disso, mobilizavam cadeias de desprezo racial que são um dos elementos estruturantes dos espaços escolares brasileiros.

Enfim, lidávamos também fundamentalmente com medos, sofrimentos, angústias, negação do próprio ser e questionamento de experiências intensamente vividas pelos sujeitos. Portanto, não nos restringíamos ao cognitivo, pois nossa ação didática antirracista nos mobilizava a propor uma mudança profunda, ao mesmo tempo cognitiva e emocional. Era uma batalha cotidiana em que não bastava dizer repetitivamente, com exemplos ou com denúncias, que uma criança ou jovem negro, que não se considera como tal, precisa de um reconhecimento e se reconhecer. E nossas palavras eram quase explicitas no coração das pessoas: mudanças numa educação antirracista, só podem acontecer, se a mesma criança ou jovem negro, conseguir superar medos, angústias e saber - sentindo - dos riscos e possibilidades de se assumir negra numa sociedade racista. Era uma operação que não iria se estabelecer na ordem simples do discurso ou através de uma técnica (didática) racional e planejada, pois o racismo não é somente pensado, mas fundamentalmente sentido enquanto dor, enquanto violência emocional diária que compromete a integridade e a dignidade humana. Era um trabalho de sísifo ${ }^{2}$, pois ao mesmo tempo não existia uma legitimidade política e jurídica.

Entretanto, surge a lei 10.639 em 9 de janeiro de 2003 e, no ano seguinte, as DCNERER que, como uma granada, explode nas reuniões pedagógicas e são cobradas pelos militantes externos às escolas, são divulgadas e se transformam em objetos de estudo e reflexões em diversas universidades. Enfim, a legislação adentra as escolas e, no nosso caso, a acusação daqueles que diziam que "víamos racismo em tudo" cai por terra. A lei 10.639/03 se transforma num artigo da LDBEN e, a cada questionamento ou defesa do mito

\footnotetext{
${ }^{2}$ O mito de Sísifo é um ensaio filosófico escrito por Albert Camus de 1941. O último capítulo compara o absurdo da vida do homem com a situação de Sísifo, um personagem da mitologia grega que foi condenado a repetir eternamente a tarefa de empurrar uma pedra até o topo de uma montanha, sendo que, toda vez que estava quase alcançando o topo, a pedra rolava novamente montanha abaixo até o ponto de partida por meio de uma força irresistível, invalidando completamente o duro esforço despendido (Fonte: Wikipedia)
} 
da democracia racial, nós "batíamos na mesa" e contestávamos: "mas vocês não defendem a LDBEN? "Então, agora podemos falar de racismo e antirracismo sem estar fora da Lei!"

Esta situação, anos mais tarde, foi pensada por militantes negros que passaram a caracterizar essas ações como iniciativas dos "agentes da Lei”. Este termo foi utilizado pelo professor Amauri Mendes Pereira no XXIV Simpósio Nacional da Associação Nacional de História (ANPUH) em 2007 e refere-se à condição dos divulgadores e dos cobradores da aplicação da Lei 10.639/03. Ironicamente, este professor afirmava que se, em anos anteriores, muitas das ações dos movimentos sociais se encontravam na "ilegalidade", agora, com uma Lei que "instrumentaliza" negros e negras a lutarem contra o racismo, os defensores dessa legislação são mais do que "militantes" são os "agentes da Lei”, ou seja, sujeitos que, numa condição análoga a dos militares, governos ou juízes, exigem o cumprimento da Lei 10.639/03, se encontrando numa posição "contraditória", pois ocorre uma inversão de papeis sociais, ou seja, são os "governados" que exigem a aplicação jurídica da Lei 10.639/03 e punição dos infratores. Este momento da ANPUH foi a primeira vez que ouvimos este termo, mas, segundo o mesmo professor, esta expressão já estava sendo recorrente em diversos espaços acadêmicos e políticos.

Evidentemente, tínhamos um instrumento poderoso em mãos e, nos anos seguintes, junto com outras parcerias em dezenas de escolas no Rio de Janeiro, articulamos diversas redes de apoio e ações conjuntas, que geraram processos articulados com uma rede nacional e estadual de militantes ativistas e intelectuais negros.

Entretanto, com esta pequena história, o mais importante na análise é o fato de explicitar a militância, a dedicação organizada em ações múltiplas, a insurgência cotidiana que educa gerações e corações, a desobediência epistêmica e política, muito além do aspecto formal escolar ou acadêmico. Obviamente que um instrumento poderoso expresso numa legislação contribui muito numa ação militante, porém, como queremos argumentar, leis e normativas no plano governamental ou jurídico, são decorrências da vida real, sentida, pulsada e experienciada com dor e emoção.

Portanto, sob o espectro que ronda as questões raciais e o antirracismo na educação brasileira diante da ameaça do fim das legislações antirracistas, há que se pensar, no sentido forte do termo, em aprimorar a organização e aprofundar as contradições para construir uma nova consciência, ou seja, continuar o que fizemos sempre, mas com mais rigor teórico e mais militância. Rigor teórico aqui significa estreitar as alianças entre universidades e 
escolas na medida em que o pensamento crítico antirracista é forjado nesses dois lugares de produção de conhecimento. Por outro lado, militância aqui significa alçá-la como um conceito gerador não somente de ações e proposição políticas, mas também como produtora de novas perspectivas de conhecimento da realidade. Entretanto, cabe aqui uma reflexão antes de terminar esta seção.

Convivemos no atual período histórico com duas gerações de educadores, uma que foi socializada em ambientes educacionais em que legislações antirracistas não existiam e outra geração que entrou nos sistemas de ensino (sendo estudante ou docente) presenciando ações militantes e governamentais a partir das legislações antirracistas que os conscientizaram (em vários níveis). Demarcar esta diferença é importante para se pensar ações coletivas insurgentes nos espaços educacionais diante de uma conjuntura extremamente desfavorável. Isto porque as experiências dos sujeitos formam expectativas e enunciações possíveis sobre ações que visam possibilidades de transformações pedagógicas.

Por um lado, os sujeitos que se formaram sob o espectro do mito da democracia racial e não tinham o apoio político de legislações e de direitos jurídicos minimamente garantidos, ou tiveram que necessariamente optar por uma militância a contrapelo, ou seja, se engajar cotidianamente numa luta ou, não tinham consciência, por força daquele mesmo mito, de que a questão racial era uma questão relevante nos processos educacionais. Decorre daí, para aqueles sujeitos antirracistas, uma experiência de engajamento que os formou a partir de uma perspectiva cognitiva e emocional utópica, no sentido de que um horizonte de possibilidade e espera (de esperançar ativo) mobilizava suas ações e intenções pedagógicas e políticas. Esses sujeitos têm em sua formação geracional, experiências marcadas fortemente pela militância e pelo engajamento tático e estratégico em suas intencionalidades. Se consultarmos várias pesquisas, artigos e teses e dissertações, veremos como o movimento negro, a intelectualidade negra e os militantes e ativistas, foram capazes de produzir, embora as relações estruturantes do racismo na educação não tenham se transformado substancialmente desde então.

Por outro lado, existem os sujeitos mais jovens, com outras experiências marcantes em suas formações. Se formaram e se engajaram a partir de uma mobilização das gerações anteriores, porém não vivenciaram, como dissemos anteriormente, o trabalho de "sísifo". Quando adentram aos espaços educacionais, as legislações e direitos jurídicos adquiridos já 
existiam e mobilizavam (a partir de sua e das gerações anteriores) intencionalidades e ações pedagógicas. Diferente de gerações anteriores, esses sujeitos se amparam naquilo que está instituído legalmente, não tendo experenciado nenhuma relação de engajamento duro e por vezes violento contra o racismo, mas tendo como recurso o amparo da Lei. A consciência formada não foi a partir de processos de engajamento "fora da Lei", mas na defesa da Lei. Não que essa consciência seja menos significativa ou inferior as gerações anteriores, mas sua característica tem uma certa base de sustentação, ou seja, está amparada por dentro das instituições estatais com suas hierarquias e limites. Porém, há que se destacar que esta geração "formada pela lei”, também vivenciou profundos processos de conscientização, na medida em que foi percebendo os limites institucionais do estado racista e colonial. Muitas dessas experiências, num primeiro momento, se acenderam com a crescente mobilização antirracista na educação, porém, com uma reflexão coletiva, junto ou não as gerações anteriores, começaram a perceber os limites, os entraves, os desafios e os profundos conflitos que pesam sobre uma intencionalidade antirracista na educação.

Esta reflexão deveria ser objeto de mais pesquisas, pois, como estamos tentando desenvolver aqui, mais do que proposições e retóricas antirracistas, a experiência da luta antirracista requer uma profunda vontade utópica daqueles que pretendem agir no mundo para construir processos formativos transformadores. E isto não requer somente uma formação pedagógica e teórica fundamentada em processos cognitivos formais pois,

Em muitas situações de ação de movimento, os sujeitos que dele participa, colocam em jogo sua condição existencial ou parte importante de sua vida. Em algumas situações, suas vidas são colocadas em situações de risco. Pois, algumas mobilizações sociais se caracterizam como situações de risco para certos indivíduos e coletivos: arriscando o emprego, a segurança, a identidade, a vida. Essas ações e riscos deixam marcas viscerais e estas as fazem aprender e ensinar para novas ações e geram conhecimentos sobre a realidade, constroem memórias coletivas, ou seja, constroem sua própria história (OLIVEIRA, 2015, p. 177)

Mais do que uma tarefa acadêmica, analítica e descritiva, o que se coloca para um conjunto significativo de militantes, docentes, estudantes e intelectuais negros e não negros, é uma tarefa política de insurgência permanente na realidade educacional brasileira e, aqui, tentamos arriscar três níveis de intervenção insurgente: nas escolas junto aos docentes, as crianças e aos jovens; nas universidades junto aos jovens e na militância política comunitária cotidiana. 
Um trabalho crucial de ações pedagógicas insurgentes se desenvolve nas escolas. Aqui se encontra a base de todo o trabalho numa perspectiva utópica, é uma aposta no futuro, é o caminho que nos leva a várias direções possíveis, é o lugar onde podemos aprender a desaprender e reaprender novos horizontes de transformações políticas.

Com os docentes nas escolas é o trabalho político de aprender/educar/transformar, é viver junto/com e a partir deles os desafios permanentes do fazer educativo. Com os docentes, se aprende o fazer educação na medida em que eles enfrentam as urgências e as incertezas das relações pedagógicas e, nessas, eles produzem um novo conhecimento e a matéria prima da transformação, que é a perspectiva da mudança e do avanço do pensamento para uma vida bem vivida, para construção de repertórios sociais e culturais transformativos. Evidentemente, se faz necessário estar presente em todas as suas lutas por direitos e por dignidade profissional, ao lado/com suas mais legítimas demandas sociais.

Com as crianças é o saber cuidar, proteger e defender suas vidas. Crianças não são tábula rasa, elas são carregadas de razões, emoções e observações atentas sobre os adultos que estão ao seu redor. Mas, há "crianças" e "crianças". Nosso foco político, numa perspectiva antirracista, deve girar para as crianças mais vulneráveis e negras. Há que se investir nossas energias pedagógicas na defesa intransigente dos direitos delas, há que se combater toda a forma de violência, racismos e exclusões contra as crianças. Obviamente, não temos o poder de interferir em todos os momentos de socialização das crianças, entretanto, o exemplo ético e político deve permear todas as nossas ações pedagógicas. Por uma questão simples: educadores são também sujeitos que marcam a ancestralidade das novas gerações, pois todos nós temos uma história marcante de vida em que, os que nos educaram, sempre estão impressos em algum momento de nossas narrativas de coração. Dessa disputa de futuro, não podemos nos esquivar, pois somos finitos e são as novas gerações que nos manterão vivos e que poderão manter a chama utópica do bem viver.

Com os jovens se faz necessário, além do exemplo ético-político, a sensibilidade de aprender com eles. Dos jovens podem partir as ideias de autogestão, de questionamento das hierarquias estabelecidas pelos adultos e de criação de novas formas de organização coletiva e simbólica. Além disso, podemos identificar em vários momentos das ações dos jovens, algumas críticas profundas em como a escola não consegue perceber as 
especificidades da juventude. Um exemplo, é esta crítica de jovens italianos nos anos de 1960, às posturas da escola em relação a suposta timidez de jovens camponeses:

Cara senhora,

você nem se lembra do meu nome. E você reprovou muitos. Mas tenho pensado muitas vezes em você, nos seus colegas, nessa instituição que se chama escola, e nos meninos que foram "rejeitados". Nos rejeitaram nos campos e nas fábricas e nos esqueceram. Dois anos atrás, no primeiro ano, você me intimidava.

Além disso, a timidez me acompanhou durante toda minha vida. Desde pequeno não levantava os olhos do chão. Rastejava pelas paredes, para não ser visto. No começo eu pensei que era uma doença minha ou da minha família. Minha mãe era daquelas que diante de um telegrama se intimidava. Meu pai observava e escutava, mas não falava. Mais tarde, eu acreditava que a timidez era apenas um mal dos camponeses (...) Agora eu vi que os trabalhadores deixam aos filhos mimados todas as posições de responsabilidade nos partidos políticos e todos os postos no parlamento. Então, eles são como nós. E a timidez dos pobres é um mistério muito antigo. Eu não sei como explicar (...). Talvez a timidez não seja nem covardia nem heroísmo. É apenas falta de prepotência (SCUOLA DI BARBIANA, 1996, p.9-10)

Dessas críticas, surgem novas formas de aprendizagens. Coletivos de jovens se auto organizam para aprender e ensinar. Enfim, de um presente vivido entre autonomia e opressão, se tenta construir um futuro.

As juventudes precisam ser compreendidas naquilo que é a sua potência, ou seja, a reinvenção do mundo é mais possível do que nós adultos possamos imaginar. E, no que diz respeito a juventude negra, se faz urgente a denúncia de seu extermínio e a defesa intransigente de suas vidas.

\section{ANTIRRACISMO NAS UNIVERSIDADES}

Quando pensamos no trabalho com jovens nas universidades, uma reflexão preliminar se faz necessário do nosso ponto de vista: a produção de conhecimento é para que e para quem? Essas perguntas são cruciais para uma perspectiva política que defendemos aqui. E isto nos leva a uma reflexão recente que fizemos em outro momento:

Nas ciências sociais e da educação aprendemos que não podemos ser militantes em nossas pesquisas, isto por que aquilo que estudamos e pesquisamos devem ser objetos de análise, ou seja, ter um caráter analítico e não normativo, pois a pesquisa tem como horizonte saber investigar aquilo que não conhecemos e não aquilo que queremos para nossas vidas. Na esteira dessa concepção se encontra o significado daquilo que diversos cientistas denominam de neutralidade axiológica. Ou seja, a postura cientifica exige a isenção de valores numa investigação, nenhum procedimento científico pode conter uma resposta sobre a desejabilidade de uma 
coisa. A natureza da ciência é testar, experimentar sem um julgamento de valor de quem está investigando (OLIVEIRA e CUNHA, 2017, p. 55-56)

Esta concepção ainda é dominante nos espaços acadêmicos e, na atual conjuntura política, falar em militância dentro do contexto universitário parece dar armas e argumentos para a ultradireita, já que esta também é herdeira da matriz colonial de poder defensora da neutralidade axiológica.

Entretanto, a realidade é muito mais complexa que possamos imaginar e o que nos cabe num contexto extremamente adverso é a postura da desobediência epistêmica, como formulado por Mignolo (2008), qual seja: permitir e fomentar que pensamentos não hegemônicos adquiram status científicos a partir de seus próprios enunciados e que dialoguem entre si e com os conhecimentos hegemônicos, porém, não se curvando diante das hierarquias pré-estabelecidas pelo pensamento ocidental eurocêntrico.

Fanon (Apud, MIGNOLO, 2008) afirmava que para um negro que trabalha numa plantação de açúcar [nas Antilhas], a única solução é lutar, mas que ele "a empreenderá e a conduzirá não após uma análise marxista ou idealista, mas porque, simplesmente, ele só poderá conceber sua existência através de um combate contra a exploração e a fome" (2008, p. 186).

Essa afirmação de Fanon, formulada a partir de uma análise das relações sociais entre negros e brancos no colonialismo, também pode ser referenciada para pensar a nossa época e os nossos contextos de aprendizagens institucionalizados na academia com os jovens. Pois, diante de tantas opressões cotidianas, também presentes nos espaços universitários, não há como não lutar, não há como concordar com o paradigma da neutralidade. Na medida em que os movimentos sociais se posicionam e se afirmam como existentes, o campo do conhecimento hegemônico é posto a prova e não há mais como negar a presença das mulheres, dos jovens das periferias, dos negros, dos homossexuais, dos trabalhadores do campo etc., nas diversas universidades brasileiras. Em movimento, esses sujeitos anunciam que existem outras formas de pensar o mundo, outras formas de projetar a vida e que é necessário reorganizar a condição humana superando a condição subhumana. Assim, o foco no trabalho acadêmico com as juventudes deveria nos conduzir a ideia e práxis de que quaisquer processos educacionais que se pretendem focar numa educação crítica e de qualidade, só tem a possibilidade de serem como se pretendem se forem engajadas e insurgentes. No mais, a possibilidade de não realização desta perspectiva, 


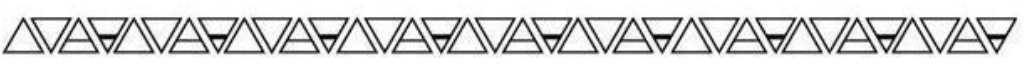

significa nossa própria derrota geracional diante dos ataques neoliberal/conservador/fundamentalista/racista/capitalista à educação brasileira.

Todos nós somos sujeitos produtores de conhecimento e somos mobilizados por uma inquietação intelectual, que tem sua matriz na realidade concreta em que ele está implicado. Paulo Freire (1987) nos diz que a cultura não pode ser arrancada do sujeito, pois este só existe porque a cultura lhe é constitutiva. Implicado em sua realidade, este sujeito não tem como ser objetivado para fora de si. Portanto, a neutralidade não existe e, o combate a ela, é a desobediência epistêmica.

\section{ANTIRRACISMO NOS ESPAÇOS COMUNITÁRIOS}

A luta antirracista insurgente fora dos espaços institucionais de ensino, mas conectados a estes, requer a compreensão de duas dimensões fundamentais: a força do mito da democracia racial e a colonialidade do ser.

Segundo Munanga (1999), o discurso da mestiçagem foi uma estratégia inteligente das elites para evitar, tanto o aparecimento explícito do racismo quanto a dominação cultural branco-europeia. $\mathrm{O}$ autor afirma que a miscigenação não foi voluntária, mas fator do desequilíbrio demográfico entre homens e mulheres brancas. $\mathrm{O}$ "mulato", afirma o autor, nasce de uma relação imposta pelo branco sobre a mulher negra e índia. Neste sentido, estabelece-se, desde a colônia, um contingente populacional mestiço grande que cumpriu um papel intermediário na sociedade com tarefas econômicas e militares na opressão aos africanos escravizados e seus descendentes. Esse fator crescente de miscigenação imposta exerceu direta influência no pensamento social brasileiro e no imaginário popular. A decorrência desses movimentos foi a teoria da democracia racial, ou seja, a ideia de que a diferença entre grupos étnicos não se constitui como fator de desigualdade.

Ainda segundo Munanga (1999), a contribuição de Freyre (1971) nos anos de 1930 é ter demonstrado que negros e mestiços tiveram contribuições positivas na cultura e identidade nacional; entretanto, ao transformar a mestiçagem em valor positivo, e não negativo sob o aspecto da degenerescência, Freyre formula os contornos de uma identidade nacional que há muito tempo vinha sendo desenhada. Ou seja, ele consolida a possibilidade de uma interpretação de um mito de origem da sociedade brasileira, baseado na harmonia 
das três raças, onde, da dupla mistura - biológica e cultural - brota lentamente o mito da democracia racial.

Este mito, apesar de ter sofrido significativos ataques culturais, epistêmicos e políticos, ainda se mantém como base explicativa da constituição das relações sociais brasileiras. O movimento social negro que fez com que os debates raciais na sociedade brasileira ganhassem visibilidade, evidenciando que existe uma condição racial subalterna em relação àquela construída sob a hegemonia branca, estabelece muitos conflitos subjetivos e sociais. O mito da democracia racial ainda é forte, e tende a se acentuar numa conjuntura conservadora. Ele se constitui ainda como uma retórica mobilizadora de explicação da realidade brasileira.

A outra dimensão é a colonialidade do ser. Este conceito se refere à experiência vivida da colonização e seus impactos na linguagem, que responde à necessidade de explicitar a pergunta sobre os efeitos da colonialidade na experiência da vida e não somente na mente dos colonizados.

Catherine Walsh (2005) recorda as palavras de Frantz Fanon (1983) para relacionar colonialismo a não existência: "em virtude de ser uma negação sistemática da outra pessoa e uma determinação furiosa para negar ao outro todos os atributos de humanidade, o colonialismo obriga as pessoas que ele domina a perguntar-se: em realidade quem eu sou?" (Fanon, apud. Walsh, 2005, p. 22). E mais:

O mundo colonial é um mundo maniqueísta. Não basta ao colonizador limitar fisicamente o colonizado, isto é, com seus policiais e guardas, o espaço do colonizado. Como que para ilustrar o caráter totalitário da exploração colonial, o colono faz do colonizado uma espécie de quintessência do mal. A sociedade colonizada não é apenas descrita como uma sociedade sem valores. (...) O indígena é declarado impermeável à ética. Ausência de valores, e também negação dos valores. Ele é, ousemos dizer, o inimigo dos valores. Neste sentido, ele é o mal absoluto. Elemento corrosivo, destruindo tudo de que se aproxima, elemento deformante, desfigurando tudo o que se refere à estética ou à moral, depositário de forças maléficas (...) (FANON, 2005, p. 57-58).

A colonialidade do ser é pensada como uma negação de um estatuto humano para africanos e indígenas, por exemplo, na História da modernidade colonial. Esta negação, segundo Walsh (2007), implanta problemas reais em torno da liberdade, do ser e da História do indivíduo subalternizado por uma violência epistêmica.

A violência epistêmica se constrói em torno ao conceito de raça, no qual novas categorias foram criadas como branco, negro, índio, mestiço etc., e relaciona sujeitos numa 
classificação social de forma vertical. Maldonado-Torres (2007) deduz daí que a ideia de seres não europeus como inferiores produziu formas de desumanização. Por outro lado, Dussel (2009) afirma que a negação que o ser europeu faz do outro colonizado, a forma como desconhece a alteridade e o modo como relega o diferente, o converte em um não-ser. Esta, portanto, foi a experiência vivida na colonialidade.

Maldonado-Torres vai mais longe e afirma que o privilégio do conhecimento na modernidade e a negação de faculdades cognitivas nos sujeitos racializados, fornecem as bases para uma negação ontológica do outro não europeu. Ou seja, a ausência da racionalidade está vinculada na modernidade com a ideia de ausência de ser nos sujeitos racializados. Neste sentido, podemos entender melhor a ideia de Fanon de que, em um mundo anti-negro, o negro não tem resistência ontológica diante dos olhos dos brancos (FANON, 1983).

Seguindo as formulações de Fanon sobre os condenados da terra, Maldonado-Torres (2007) caracteriza também a colonialidade do ser como experiências invisibilizadas, não como simples sujeitos, mas na sua própria humanidade. Esta seria uma das expressões primeiras da colonialidade do ser.

O mito da democracia racial e a colonialidade do ser produzem relações sociais estruturantes no cotidiano brasileiro e se conecta estreitamente com processos escolares e universitários. O não branco, na maioria das situações cotidianas, vive numa zona de "nãoser”: não tem capacidades cognitivas, não tem autoridade política, não é autorizado a ocupar certos espaços, enfim, ao negro, especialmente as mulheres negras em muitos momentos, são somente uma mercadoria, objeto de desejos sexuais ou herdeiro de um tempo de escravidão que, por sua natureza não humana, não conseguiu superar. Por outro lado, essas visões não são assumidas pela maioria de brancos ou daqueles que incorporam a branquitude. Assim, como é possível um trabalho de base, onde por um lado se desumaniza negros e negras e, por outro, se nega a existência dessa desumanização?

Diferentemente de um trabalho político-sindical, onde uma reivindicação concreta por direitos mobiliza contra uma situação de injustiça explícita, ou seja, baixos salários, ausência de cumprimento de legislações que garantem direitos sociais ou a ausência de direitos políticos, o racismo é negado pela ampla maioria das pessoas. Sendo negado, subjetivamente e objetivamente, a reivindicação por direitos iguais e equânimes em relação a brancura, se posiciona na contramão de um dado real considerado natural, como a lei da 
gravidade.

A luta contra o racismo em espaços comunitários, onde o cotidiano nega o racismo, é um trabalho político de longo prazo. Ela não pode ter a ingenuidade de que a curto e médio prazo o racismo vai acabar ou vai ser neutralizado por uma retórica antirracista.

O trabalho antirracista envolve a dedicação militante em todos os momentos da vida de negr@s e branc@s antirracistas. Mas o que é ser militante antirracista? Como se insurgir contra as práticas racistas? As respostas a estas perguntas não possuem uma receita de bolo. O que podemos apontar são simplesmente algumas pistas.

O professor da UFRRJ Amauri Mendes Pereira, em um debate sobre relações raciais na mesma universidade, certa vez foi questionado se brancos podem ingressar na luta contra o racismo. Sua resposta foi enfática contando um momento de sua história de vida.

Nos anos de 1970 ele estava procurando uma escola para lecionar Educação Física. Um de seus amigos (branco) lhe disse que foi chamado numa escolar particular e, em sua entrevista, além de terem ficado satisfeitos com seu perfil e sendo admitido, lhe perguntaram se ele conhecia algum professor de Educação física, pois a escola estava precisando de um, urgentemente. Esse amigo imediatamente indicou o professor Amauri. Dias depois, Amauri se dirigiu a escola e se apresentou para a vaga ofertada. Entretanto, ao vê-lo, o entrevistador afirmou ao professor Amauri que a escola não precisava de nenhum professor de Educação Física. A reação do professor foi de estranheza, pois seu amigo tinha lhe informado sobre a urgência da escola em ter um profissional em sua área. Em seguida o professor Amauri retorna a conversa com seu amigo sobre o ocorrido. O que faz esse seu amigo? Retorna a escola para perguntar por que Amauri não foi contratado. A resposta foi típica: "ele não se encontra no perfil da escola". Imediatamente, esse amigo percebe que a questão não é o perfil profissional, mas a postura racista da escola. Depois dessa conversa, esse amigo (branco) diz que não pretende mais trabalhar numa escola racista e que não aceitaria jamais um trabalho onde o critério de seleção de docentes é a cor de pele branca.

O professor Amauri, com esta resposta a indagação feita por parte de uma estudante, quis dizer explicitamente que o problema racial no Brasil não é uma coisa "só do negro" e que brancos antirracistas precisam ser fortes aliados junto a população negra. E pergunta: quantos estão dispostos a fazer isso? E quando fazem isto, precisamos desconfiar dos brancos por que são brancos? Essa pequena história nos diz que a luta racial deveria 
significar uma luta de toda a sociedade brasileira. Outra história vem de um município do interior do estado do Rio de Janeiro, o município de Macaé.

Era o ano de 2005. Dois professores realizavam um minicurso sobre relações raciais numa escola dos anos iniciais do Ensino Fundamental. Neste minicurso, se abordavam temas como racismo, raça, história da África e relações raciais em sala de aula. Debates profundos durante 4 semanas seguidas. Na última semana, no momento de finalização e avaliação coletiva, uma professora alfabetizadora deu o seguinte depoimento: "esse curso me fez perceber uma coisa chocante. Nunca tinha percebido que minhas dez crianças que alfabetizo, são negras”. E mais: “depois deste curso entendi que o conceito de 'negro' não é pejorativo. Antes eu ficava com medo de expressar esta palavra, pois sabe como é, era um receio de estar ofendendo alguma criança".

Apesar da satisfação que os professores que ministravam este curso tiveram, pois representou um avanço nos debates sobre consciência antirracista, alguns minutos depois a mesma professora fez uma pergunta que ficou sem resposta: "mas, professor, aprendi aqui a não mais ter medo de classificar uma criança negra de negra. Mas, se os pais dessa criança não gostarem dessa classificação e tentarem me intimidar ou denunciar? O que devo fazer?"

Essa última fala perturbou a todos ali presente. A resposta não era simples, pois exigia mais 16 horas de curso, ou, como refletimos alguns anos depois:

Depois de alguns dias, me dei conta de que as professoras tinham muitas ideias sobre o racismo no Brasil, mas também interpretei que elas me deram um recado: como discutir a História da África, o racismo, os preconceitos, se nós temos muitas coisas para resolver, principalmente os preconceitos contra nós mesmos e contra nossas crianças? Essa questão me perseguiu durante os anos subsequentes. E fui amadurecendo a ideia de que para se discutir a Lei 10.639/03 com os professores, era necessário ir além, ou seja, na complexidade da formação docente em termos subjetivos e objetivos (OLIVEIRA, 2012, p. 264).

Dez anos após esta história, vivenciamos outra, agora num contexto envolvendo a relação entre professor e estudante de pós-graduação.

Era o ano de 2014 e uma pedagoga se apresenta ao professor numa disciplina de mestrado na UFRRJ denominada "Colonialidade e Racismo Epistêmico: formação docente e relações raciais". Seu objetivo não era somente cursar uma disciplina de um tema que ela nunca estudou, mas também conhecer o professor que poderia ser seu futuro orientador.

Nos primeiros debates, ela quase não se expressava. Quando o fazia, descrevia suas dificuldades em debater sobre racismo e sobre sua identidade racial (dizia ela que outras 
pessoas a atribuíam, as vezes como mulata, as vezes como parda). Os colegas em torno, a abordavam carinhosamente no sentido de tentar mobilizá-la para todo um debate já acumulado por eles, afirmando que essa reflexão é um processo longo e doloroso, pois não é fácil o reconhecimento da própria condição racial. Não fizeram uma abordagem agressiva no sentido de exigir que ela se assumisse enquanto negra, mas na perspectiva de que somente ela poderia perceber se negra ou não. Cabe ressaltar aqui que esta pedagoga se apresentou com seus belos cabelos lisos e, por algum tempo, continuou assim.

Durante esses primeiros momentos, ela iniciou seu processo de seleção ao mestrado e, após provas e entrevistas, consegue ser selecionada em 2015 para o mestrado em educação. A partir daí muita coisa mudou, pois começou a priorizar a compra de livros, a leitura de textos, a participação em eventos acadêmicos e de movimentos sociais negros, a participação em grupos de pesquisa e, o mais importante, em fazer do debate sobre o racismo uma rotina na família e nos seus círculos de amizade. Outra mudança foram os diversos eventos aos quais ela participou enquanto protagonista (sendo palestrante, mediadora ou apresentando trabalhos). Decorre daí também, a mudança corporal: não alisou mais os cabelos e adotou o visual "natural", a saber, os "cabelos afros".

Estas histórias nos remetem a uma perspectiva de pensamento político e analítico fundamental: somente o nível da argumentação e da retórica antirracista não é suficiente para um avanço da luta contra o racismo, é preciso ir mais além. Essas experiências nos informam que a retórica antirracista é relevante, mas o mais significativo é a experiência dos sujeitos na pele, na dor, no sentimento de negação, no medo, na consciência do desprezo, ou seja, afetos que também movem os sujeitos muito além dos interesses estruturais e econômicos. E, no campo dos afetos, mesclados com a argumentação, é que talvez possamos avançar pedagogicamente em espaços não institucionalizados.

O enfrentamento ao racismo é um conflito que mobiliza o desprezo, a dor, a ansiedade, o medo, o não lugar, enfim, a insegurança humilhante do não reconhecimento enquanto ser e sujeito. O que se faz necessário é a militância e engajamento num outro sentido, na medida adequada para a construção de outras experiências de sociabilidade.

Outro exemplo pode ser considerado nesta perspectiva, que desenvolvemos recentemente (OLIVEIRA, 2019):

No samba de roda todas as pessoas são chamadas a dança, mesmo que algumas delas não saibam mexer o corpo, ou seduzir o grupo. Além disto, o elemento 
principal da dança não é a demonstração das habilidades de cada um, da capacidade de dançar, mas a confraternização do grupo, criar a harmonia comunitária através da linguagem corporal, pois o corpo é um dos centros sagrados do mundo. (2019, p. 57).

No samba de roda a realização de cada um é a realização do grupo, em função da alegria coletiva. Na realização pessoal de cada um dentro do grupo, toda a roda toma parte do bailado. Assim, diferenciando-se das estruturas de organização da escola e de seus discursos, o samba de roda se caracteriza como um recurso pedagógico, um meio permanente de iniciação à sabedoria e da sociabilidade do grupo. (OLIVEIRA, 2019, p. 58).

As dinâmicas das culturas negras de matriz africana, podem nos mostrar que existem outras formas de construir pedagogicamente uma sociedade mais justa e mais igualitária. O Samba de Roda e as danças africanas, nos permitem e exibem um outro método de convivência democrática entre pessoas e grupos.

Samba de Roda é um folguedo e uma herança africana, constituído de danças, passos muito requebros, umbigada e cantoria. O ritmo é marcado por atabaques, pandeiros, berimbaus e batidas de palmas. No Recôncavo Baiano o samba de roda é uma forma típica de samba, geralmente dançado somente por mulheres, cuja coreografia se desenvolve no círculo de participantes, tendo ao centro uma solista, que executa movimentos ágeis e graciosos, acompanhados de instrumento de percussão e de palma. Oliveira (2019) ainda afirma:

Nestas manifestações culturais, se expressa uma visão de mundo muito peculiar trazida pelos africanos escravizados e reconstruído pelos afrodescendentes. Ou seja, a dança negra é um meio de identificar um consenso comunitário, uma harmonia participativa, onde todas as pessoas devem colocar suas qualidades $\mathrm{e}$ potencialidades em benefício do grupo. Além disso, não podemos esquecer que a dança negra, no contexto da opressão escravista, era também um meio de afirmação pessoal, graças ao qual o descendente de escravo deixava de sentir-se objeto da ação para converter-se em agente do mundo (OLIVEIRA, 2019, p. 55)

Para Muniz Sodré (1988), a dança negra faz parte de um elemento da cosmologia africana, é um "sentir, mas de uma experiência radical, de uma comunicação original com o mundo, que se poderia chamar de cósmica, isto é, de um envolvimento emocional dado por uma totalização sagrada de coisas e seres” (1988, p. 137). E mais:

O samba de Roda expressa muito bem essa maneira de ser de um povo, que procura se construir na coletividade, não tendo outra alternativa. E a roda respeita cada participante como ele é, e com a contribuição que ele tiver. Em todos os momentos, cada um é o centro e nesse momento e por alguns momentos ele ou ela é o dirigente máximo do processo, ou melhor dizendo, da roda. No centro da roda cada um faz o que pode e o que sabe, não existe uma exigência. De certa forma é um exercício da plenitude humana e da construção da cidadania, é um movimento alegre e festeiro, 
como tem que ser a vida nessa visão de mundo, em que a cada momento, uma pessoa é o centro da roda, é observado por todos, como também de certa forma, ensina a todos. Nesse momento dar-se a plenitude da pessoa. O samba de roda nos ensina a sermos profundamente democráticos e acreditarmos nesse princípio como um valor importante na construção do processo coletivo. Ela também nos ensina a lidar com a alternância de poder. O poder que precisa ser compartilhado, socializado. Ela também nos ensina o respeito a todos, as várias alternativas, posições, expressões, as diferenças. É uma lógica interessante pelo respeito as diferenças. É uma relação profundamente coletiva no envolvimento, na sedução, na participação e no papel de direção. (OLIVEIRA, 2019, p. 55-56)

Estes exemplos nos permitem especular: por que não aprendemos a desenvolver um trabalho político insurgente semelhante aos processos de resistências e afirmações de nossos ancestrais? Estes, fizeram política permanente e num período histórico em que, por exemplo, políticas públicas de Estado eram inimagináveis.

Este nos parece ser o sentido profundo da desobediência epistêmica e da insurgência política, ou seja, afirmar processos e dinâmicas outras fora da lógica hegemônica, a partir dos conhecimentos negros, populares e subalternizados que se forjam nas lutas concretas contra a opressão, o patriarcalismo, o capitalismo, o sexismo e o racismo.

Por fim, este texto se apresenta como uma pequena contribuição epistêmica e política, na medida em que a conjuntura histórica que presenciamos exige de nós um debate mais amplo e profundo com aqueles aos quais a modernidade ocidental invisibilizou e tentou exterminar.

\section{REFERÊNCIAS BIBLIOGRÁFICAS}

DUSSEL, Enrique. Meditações anti-cartesianas sobre a origem do anti-discurso filosófico da modernidade. In: SANTOS, Boaventura de Sousa e MENESES, Maria Paula. (Orgs.). Epistemologias do Sul. Coimbra: Edições Almedina, 2009, p. 283-335.

FANON, Frantz. Peles negras, máscaras brancas. Rio de Janeiro: Ed. Fator, 1983. . Os condenados da terra. Juiz de Fora: Ed. UFJF, 2005.

FREIRE, Paulo. Pedagogia do oprimido. Rio de Janeiro: Paz e Terra, 1987.

FREYRE, Gilberto. Casa Grande e Senzala. Rio de Janeiro: Schimidt-Editor, 1971.

MALDONADO-TORRES, Nelson. Sobre la colonialidad del ser: contribuciones al desarrollo de un concepto. In: CASTRO-GÓMEZ, Santiago. e GROSFOGUEL, Ramón. (Orgs.). El giro decolonial. Reflexiones para una diversidad epistémica más allá del capitalismo global. Bogotá: Siglo del Hombre Editores, 2007, p. 127-167. 
MIGNOLO, Walter. Desobediência epistêmica: a opção descolonial e o significado de identidade em política. In: Cadernos de Letras da UFF - Dossiê: Literatura, língua e identidade. n. 34, 2008, p. 287-324.

MUNANGA, Kabengele. (Org.). Rediscutindo a mestiçagem no Brasil. Petrópolis: Vozes, 1999.

OLIVEIRA, Luiz Fernandes de. História da África e dos africanos na escola. Rio de Janeiro: Ed. Imperial Novo Milênio/FAPERJ, 2012.

$\boldsymbol{E}$ nas lutas sociais que aprendemos? mas aprendemos o quê? algumas ideias e algumas histórias negras para a educação. in: Revista Retta. vol. VIII, n 11 , jan.-jun./2015, p. 171-194.

O samba de roda e o xirê: por uma crítica decolonial da educação bancária. In: FONSECA,

Lana. (Org.) Educação Não Formal em Espaços Religiosos: relações entre ciência, educação e religião. Belo Horizonte: Venas Abiertas, 2019, p. 45-61.

OLIVEIRA, Luiz Fernandes de e CUNHA, Lilian do Carmo Oliveira. Produzir conhecimento é um pensar militante. In: Revista Pensamiento Actual. V. 17 - N. 28, 2017, p 54-65.

SCUOLA DI BARBIANA. Lettera a una professoressa. Firenze: Libreria Fiorentina, 1996.

SODRÉ, Muniz. O terreiro e a cidade: a forma social negro-brasileira. Petrópolis: Vozes, 1988.

WALSH, Catherine. Introducion - (Re) pensamiento crítico y (de) colonialidad. In: WALSH, Catherine. (Orgs.). Pensamiento crítico y matriz (de)colonial. Reflexiones latinoamericanas. Quito: Ediciones Abya-yala, 2005, p. 13-35.

Interculturalidad crítica / pedagogía decolonial. In: Anais do Seminário Internacional

Diversidad, Interculturalidad y Construcción de Ciudad. Bogotá: Universidad Pedagógica Nacional, 2007.

Recebido 30/03/2020

Aprovado em 30/04/2020 